\title{
A procedure for obtaining young children's reports of olfactory stimuli
}

\author{
MARTHA STRICKLAND and PEGGY O. JESSEE \\ The University of Alabama, Tuscaloosa, Alabama \\ and \\ ERIK E. FILSINGER \\ Arizona State University, Tempe, Arizona
}

\begin{abstract}
Young children (ages 2 to 5 ) have proved to be difficult subjects for obtaining valid reports of their ratings of olfactory stimuli. Thirty-six preschoolers were tested on benzaldehyde (a pleasant odor) and on dimethyl disulfide (an unpleasant odor) using a smiling or frowning face as a response format. The results showed the ability of young children to discriminate between pleasant and unpleasant odors.
\end{abstract}

Although researchers have begun to address the development of olfactory abilities in children (Doty, et al., 1984; Fabes \& Filsinger, 1986), previous attempts to measure young children's ratings of olfactory stimuli have encountered a number of methodological problems. Engen (1974) found tht 4-year-old children were more likely to respond in the affirmative when asked, "Does it smell pretty," or when asked, "Does it smell ugly." Doty (in press) reports that young children tend to respond in the affirmative when "yes" or "no" is the required response. In an attempt to overcome the affirmative response set, Fabes and Filsinger had children between the ages of 3 and 6 rate odors by pointing to one of five "smile-frown" faces. They found that these children chose faces by means of systematic movement from left to right across various trials, that is, the children chose the leftmost face for the first odor, the second leftmost face for the second odor, and so on, even when the four odors used were presented in a counterbalanced order across subjects. Apparently, the procedure involved too complex a discrimination and the children applied some other rule to the task, for example, seriation.

Two- and 3-year-old children generally learn to discriminate between two stimuli before they can discriminate among three or more stimuli (Salkind \& Ambron, 1987). Symbolic discriminations occur even later, usually beginning around age 6 . Very young children can discriminate among pictures with various facial expressions long before they can differentiate among graphic symbols. Some evidence suggests that infants can learn

This research was supported in part by a grant from the Mary Crenshaw Research Award, College of Human Environmental Sciences, The University of Alabama. Special thanks must be extended to Ralph Lane for his help in preparing the olfactory stimuli and to Stephen Thoma for his suggestions on data-analysis techniques. Reprints may be requested from Martha Strickland, Director of the Child Development Laboratory, Department of Human Development, Box 1488, The University of Alabama, Tuscaloosa, AL 35487-1488. that a downward curved line represents a disapproving mouth and an upward curved line represents a smile (Salkind \& Ambron, 1987). Considering these developmental factors, the 5-point facial scale used by Fabes and Filsinger (1986) may have been inappropriate for odor ratings. A 2-point scale (smile vs. frown) may be more appropriate. It is clear that improvements are necessary in the laboratory protocol for assessing reports of young children's responses to olfactory stimulation. The present study reports on a technique that obtained reliable discriminations of olfactory stimuli by 3 - to 5-year-olds.

\section{METHOD}

\section{Design}

Two olfactory procedures were run using two odors. Both procedures used smile versus frown faces. One procedure, referred to as the teaching procedure, employed a pleasant odor (vanillin) and an unpleasant one (butyric acid) to demonstrate the task. The other procedure did not employ a teaching component. The two test odors used were benzeldehyde and dimethyl disulfide. The two testing procedures and the two odors were presented in a counterbalanced order so that four different groups were formed, each with a different sequence of odor and test combinations.

\section{Subjects}

Thirty-six preschoolers (19 males and 17 females) attending classes at the Child Development Laboratory at The University of Alabama were included in the study. The majority of the children, who ranged from 38 months to 72 months of age, were from white middle-class families. Thirty-two percent were from black and Oriental families. There were approximately equal numbers of boys and girls at each age of 3,4 , and 5 .

\section{Materials}

In a rank ordering of preferences, benzaldehyde and dimethyl disulfide were chosen by young children as the most and least preferred odors in Fabes and Filsinger's (1986) study. However, that study failed to obtain meaningful measures of young children's olfactory responses. It was decided that a comparison with the previous findings would be enhanced through the use of the same odorants. These were benzaldehyde (Sigma No. B6259), a com- 
mon food artificial flavoring of essential oil of almond, and dimethyl disulfide (DMDS, Sigma No. D8501), a human odorant associated with saliva and sweat that appears to be produced by naturally occurring bacteria (Alberts \& Gubernick, 1983). The odorants were prepared in $0.24 \%$ solutions in glycerol, which corresponded to the concentrations used by Fabes and Filsinger (1986). The teaching odors, vanillin and butyric acid, were both prepared as $1 \%$ solutions in glycerol. At the beginning of each day, a small quantity of the solution sufficient to cover the bottom of a $500-\mathrm{ml}$ bottle was taken from a refrigerated stock supply. The wide-mouthed $500-\mathrm{ml}$ bottle served as the sniff bottle.

A $43 / 4$-in. circle formed the outline of the two faces. Seven curved lines were affixed to the top of the circle for the hair. The eyes were shaped like a half oval with a filled-in circle for the iris. Each side of the nose had outward curved lines connected by an upward curved line at the bottom. These features were the same on the smiling and the frowning face. The mouth on the frowning face had a $1 / 2$-in. downward curvature and the mouth on the smiling face had a $1 / 2$-in. upward curvature. The eyebrows on the smiling face curved downward about $1 / 4$ in. whereas the variation in curvature on the frowning face was from the center of the eyebrows toward the center of the face. This curvature continued further down and was thicker. India ink was used to draw the two faces.

\section{Procedure}

Stratified by age group, the children were assigned randomly to one of the four groups, counterbalanced by the order of presentation of test procedure and odor. Half the children were exposed to the teaching procedure prior to the testing; the other children were exposed to the nonteaching procedure first. The order of presentation of odor was counterbalanced within each procedure.

The experimenter went to each child's classroom and escorted him/her to the testing room. The experimenter (female) had had prior experience in using the testing procedures on children of approximately the same age. Rapport was established with the child. For the teaching group, the experimenter introduced the teaching procedure game. In the game two jars, one with a pleasant odor and one with an odor that was not pleasant, and two faces, one that was smiling and one that was frowning, were used.

The experimenter told the child that one jar had a smell that "makes you feel good, and when you feel good, you usually smile." Then she placed the jar on the smiling face. She removed that jar and presented a different jar to the child. She told the child that this jar "has a smell that does not make you feel good, and when you do not feel good, you usually frown." Then she placed the jar on the frowning face.

After the demonstration, the experimenter presented two glass jars with practice odors 1 , vanillin, and 2 , butyric acid. The experimenter removed the stopper and presented one practice jar at a time, moving it beneath the child's nose. The child was asked how the odor made him feel, the stopper was replaced, and the jar was given to the child to place on one of the two faces. This procedure was repeated for the second jar. Positive feedback was given when the choices were correct. If the child chose the wrong face, the experimenter clarified how the smell made the child feel and repeated the practice procedure until she was satisfied that the child understood the task requirements.

When each child successfully completed the teaching procedure, he/she was asked to play a new game that followed the same format but used the two test odors, benzaldehyde and dimethyl disulfide. As before, the experimenter removed the stopper of the first test odor, moved the jar under the child's nose, and asked the child to place the jar on the face that showed how the smell made him/her feel. The first jar was then removed. The experimenter paused for $20 \mathrm{sec}$ between the response to the first bottle and the presentation of the second. It was possible for the child to indicate successive smile or frown choices.
At the conclusion of the teaching procedure and presentation of the two test odors, the experimenter introduced the nonteaching procedure (described below) and presented the test odors again in reverse order. Thus, each child was exposed to both methods of introduction (teaching and nonteaching), counterbalanced by order of presentation.

The nonteaching procedure began with the child's being escorted into the testing room and with the establishment of rapport by the experimenter. She introduced the test situation, telling the child that they were going to play a game. She pointed to the smiling face, and said that it was smelling something good and that the frowning face was smelling something bad. The test odors, benzaldehyde and dimethyl disulfide, were then presented, one at a time, to the child. The experimenter removed the stopper, moved the jar under the child's nose, and allowed him/her to place the jar on the appropriate face. She removed the jars and told the child they were going to play the game differently. She then led the child through the teaching demonstration using practice odors. When she was certain that the child understood the task, she presented the two test odors again, in the reverse order of their original presentation.

A response on the smile face was scored a " 1 ," while a response on the frown face was scored a " 2 ." The higher the score, that is, " 2 ," the more unpleasant the olfactory stimulus.

\section{RESULTS}

The effect of order of presentation was analyzed first in a 4 (order group) $\times 2$ (procedure) $\times 2$ (odor) analysis of variance (ANOVA). Group was a between-subjects factor, while procedure and odor were within-subjects factors. The only significant effect was related to odor discrimination. Those differences are described below. There was no significant effect related to order of presentation, indicating that order of presentation did not affect the ratings of the odors.

With order-of-presentation differences ruled out, a 3 (age) $\times 2$ (procedure) $\times 2$ (odor) ANOVA was conducted to test whether or not these 3-, 4-, and 5-year-old children could meaningfully discriminate the odors. Age was a between-subjects factor, while procedure and odor were within-subjects factors.

In the test of the within-subjects odor effect, a significant main effect was observed $[F(1,33)=14.30, p<$ $.001]$. There were no significant interactions of age or procedure with odor. The means associated with this analysis are presented in Table 1. It is clear that the pleasant odor (benzaldehyde) received more positive ratings (smile) and that DMDS received more negative ratings (frown), even though the 3-year-old children did not discriminate as clearly as did the older subjects.

The main effect for procedure was not significant, suggesting that both procedures led to similar results. However, a significant interaction was found between procedure and age. Inspecting the means suggests that there was an age difference with respect to the teaching procedure but not to the nonteaching procedure. The 3year-olds provided with the teaching method rated DMDS as more pleasant (smile) than did the 4- or-5-year-olds with that procedure $(M=1.38$ vs. $M$ s $=1.80$ and 1.77 respectively). Age differences were not found between the two odors with respect to the nonteaching procedure. 
Table 1

Means and Standard Deviations of Children's Odor Preference Scores

\begin{tabular}{ccccc}
\hline & \multicolumn{2}{c}{ Benzaldehyde } & \multicolumn{2}{c}{ Dimethyl disulfide } \\
\cline { 2 - 5 } Age* & $M$ & $S D$ & $M$ & $S D$ \\
\hline \multicolumn{5}{c}{ Teaching Condition } \\
3 & 1.38 & .52 & 1.38 & .52 \\
4 & 1.27 & .46 & 1.80 & .41 \\
5 & 1.23 & .44 & 1.77 & .44 \\
\multicolumn{5}{c}{ Nonteaching Condition } \\
3 & 1.50 & .54 & 1.75 & .46 \\
4 & 1.20 & .41 & 1.93 & .26 \\
5 & 1.15 & .38 & 1.62 & .51 \\
\hline Note-N $=36$. & *In years.
\end{tabular}

The test for an odor $\times$ procedure interaction was not significant. That is, odors were rated similarly under either procedure.

When sex was added as a between-subjects factor, a sex $\times$ procedure interaction emerged $[F(1,33)=9.15$, $p<.005]$. No other main or interaction effects were significant. This interaction is due to girls' rating DMDS more negatively under the nonteaching procedure than under the teaching procedure $(M=1.70$ vs. $M=1.94)$. Boys' ratings of DMDS did not differ with respect to procedures. Gender did not seem to influence the ratings of benzaldehyde under the two procedures. These results should be considered cautiously, since the homogeneity of variance assumption in the ANOVA procedures was isolated due to zero variance in cells. Four- and 5-yearold-girls were unanimous in their pleasant ratings of benzaldehyde under the teaching conditions. Similarly, 3- and 4-year-old girls unanimously found DMDS unpleasant. No similar unanimity was observed for boys.

\section{DISCUSSION}

The results of this study demonstrated the potential of using smile and frown faces in children's ratings of olfactory stimuli. Two odors generally thought to be pleasant and unpleasant were discriminated as positive (smile) and negative (frown) by children aged 3, 4, and 5. A teaching and a nonteaching procedure of presenting the odors produced similar results. The smile versus frown choice appears to be within the comprehension range of young children. It should be cautioned that although there was no significant age $\times$ odor interaction, it still appeared, from examination of the means, that odor preferences are not as distinct for 3-year-olds as they are for older children. This finding supports earlier work that has revealed differences between young children and adults, with a transition around age 3 (Doty, in press; Engen, 1974).

In a classic study by Peto (1936), no evidence of agreeable or disagreeable reactions to the odor stimuli was shown below the age of 5 . The ages of 5 and 6 were transitional, while the children above the age of 6 demon- strated distinct preferences among odors. The present research suggests a difference between the odor discrimination ability of 3- and 4-year-olds. In addition, this study shows that 4-year-olds may also have the ability to discriminate odors if the mechanism by which they make their choices is developmentally appropriate.

Nevertheless, a difference between the results must be noted. It should be kept in mind that Peto's research was done on children who were hospitalized. Engen (1982) has indicated that olfaction is frequently distorted when an individual is ill. It may be that Peto's results do not apply more generally to broader populations. His explanations of the age change have to do with cultural conditioning between ages 5 and 6 . It may well be that cultural effects occur at an earlier age today than they did in the 1930s.

The scanning abilities of young children are limited, especially for symbolic stimuli (Sarafino \& Armstrong, 1986). Children under the age of 5 may not be able to rate odors if given a complex visual scanning task, as had been attempted by Fabes and Filsinger (1986). On the other hand, a dichotomous choice may be age appropriate for young children in rating odors by means of a visual task. The fact that no difference was found between the teaching and the nonteaching procedures may indicate the clarity of the 2-point discrimination.

The odor rating task also involved integration, that is, the transferal of information from one sensory channel to another. Research on the development of intersensory integration shows that the ability to transform information gained from one sensory system into that of another improved greatly between the ages of 3 and 6 (Sarafino \& Armstrong, 1986). Most research concerning integration of sensory systems focuses on vision and hearing or on vision and touch; perhaps more attention can be paid to children's ability to integrate the sense of smell to the visual modality.

The experimental procedure employed herein appeared to be developmentally appropriate for the joint tasks of discrimination and integration necessary to give meaningful self-reports. Further research involving olfactory preferences in young children could be enhanced by focusing on developmentally appropriate laboratory protocol.

\section{REFERENCES}

Alberts, J. R., Gubernick, D. J. (1983). Reciprocity and resource exchange: A symbiotic model of parent-offspring relations. In $L$. A. Rosenblum \& H. Moltz (Eds.), Symbiosis in parent-offspring interactions (pp. 7-44). New York: Plenum Press.

DoTY, R. L. (1986). Developmental and age-related changes in human olfactory function. In W. Breiphl \& R. Apfelbach (Eds.), Ontogeny of olfaction in vertebrates. Berlin: Springer-Verlag.

Doty, R. L., Shaman, P., Applebaum, S. L., Giberson, R., SikarskI, L., \& Rosenberg, L. (1984). Smell identification ability: Change with age. Science, 226, 1441-1443.

ENGEN, T. (1974). Method and theory in the study of odor preference. In J. W. Johnston, D. G. Moulton, \& A. Turk (Eds.), Human 
responses to environmental odors (pp. 121-141). New York: Academic Press.

Engen, T. (1982). The perceprion of odors. New York: Academic Press.

FABES, R., \& Filsinger, E. (1986). Olfaction and yound children's preferences: A comparison of odor and visual cues. Perception \& Psychophysics, 40, 171-176.

Peto, E. (1936). Contribution to development of smell feeling. British Journal of Medical Psychology, 15, 314-320.
Salkind, N. J., \& Ambron, S. R. (1987). Child development. New York: Holt, Rinehart \& Winston.

Sarafino, E. P., \& Armstrong, J. W. (1986). Child and adolescent development. New York: West.

(Manuscript received April 2, 1987; revision accepted for publication April 22, 1988.)

\title{
Notices and Announcements
}

\author{
18th Annual Meeting of the Society for Computers in Psychology \\ Chicago, Illinois \\ November 9, 1988
}

The 18th Annual Meeting of the Society for Computers in Psychology will be held at the Palmer House Hotel, Chicago, Illinois, on November 9, 1988. This meeting will feature papers on applications of computers to all areas of psychology-experimental, clinical, and educational.

Further information may be obtained from N. John Castellan, Jr., Department of Psychology, Indiana University, Bloomington, IN 47405.

\section{9th Annual Meeting of the Psychonomic Society \\ Chicago, Illinois \\ November 10-12, 1988}

The 29th Annual Meeting of the Psychonomic Society will be held in Chicago, November 10-12, 1988. The meetings will begin Thursday morning and continue until Saturday at noon. The headquarters hotel will be the Palmer House.

The program and hotel reservation cards have been mailed to members. A copy of the program will be published in the November issue of the Bulletin of the Psychonomic Society.

For further information, please contact the secretary-treasurer of the Society: Michael E. Rashotte, Department of Psychology, Florida State University, Tallahassee, FL 32306-1051 (Telephone: 904-644-2040; BITNET: Rashot@FSU). 